\title{
ESTOQUES DE CARBONO E NITROGÊNIO EM FRAÇÕES LÁBEIS E ESTÁVEIS DA MATÉRIA ORGÂNICA DE SOLOS SOB EUCALIPTO, PASTAGEM E CERRADO NO VALE DO JEQUITINHONHA - MG(1)
}

\author{
Karina Pulrolnik ${ }^{(2)}$, Nairam Félix de Barros ${ }^{(3)}$, Ivo Ribeiro Silva ${ }^{(3)}$, Roberto \\ Ferreira Novais $^{(3)} \&$ Carolina Braga Brandani ${ }^{(4)}$
}

\begin{abstract}
RESUMO
A substituição da vegetação nativa na região de Cerrado por florestas plantadas de eucalipto pode levar a mudanças nos estoques de $\mathrm{C}$ e $\mathrm{N}$ das diferentes frações da matéria orgânica do solo (MOS). Contudo, a intensidade e a direção da mudança nos teores de MOS dependem do tipo de solo, clima e manejo da área plantada. $O$ objetivo deste trabalho foi determinar o efeito do plantio de eucalipto nos estoques de C e N em frações lábeis e estáveis da MOS em região de Cerrado no Vale do Jequitinhonha, MG. O estudo foi desenvolvido utilizando-se amostras de solos provenientes de povoamentos de Eucalyptus urophylla e de áreas adjacentes com vegetação natural de Cerrado e cultivo de pastagem. Para o plantio do eucalipto, a vegetação do Cerrado foi cortada, a lenha removida e os resíduos enleirados e queimados. As plantações de eucalipto com 20 anos apresentaram teores de carbono orgânico total (COT) similares aos da vegetação de Cerrado e pastagem. Nas frações ácido húmico e ácido fúlvico (FAH e FAF), os teores de C foram de 16,6 e 17,5 \% maiores para o solo de eucalipto em comparação com os solos da pastagem, e 17,5 e 36,9 \% com os solos do Cerrado, respectivamente. O cultivo do eucalipto não reduziu o estoque de $\mathrm{C}$ e $\mathrm{N}$ da biomassa microbiana do solo (BMS) em comparação com a do Cerrado e pastagem, e proporcionou incremento nas quantidades de $\mathrm{C}$ e N na matéria orgânica leve (MOL), o que contribuiu para o aumento da MOS. A contribuição do $\mathrm{C}$ derivado do eucalipto para a MOS, após 20 anos de cultivo, foi de
\end{abstract}

\footnotetext{
(1) Parte da Tese de Doutorado do primeiro autor apresentada ao Departamento de Solos da Universidade Federal de Viçosa UFV. Financiado pelo CNPq. Recebido para publicação em maio de 2008 e aprovado em junho de 2009.

${ }^{(2)}$ Pesquisadora, Embrapa Cerrados, BR 020, Km 18, CEP 73310-970 Planaltina (DF). E-mail: karina.pulrolnik@cpac.embrapa.br

(3) Professor do Departamento de Solos, Universidade Federal de Viçosa - UFV. CEP 36570-000 Viçosa (MG). E-mails: nfbarros@ufv.br; ivosilva@ufv.br; rfnovais@ufv.br

(4) Estudante de Mestrado, Departamento de Solos, UFV. E-mail: carolbrandani@yahoo.com.br
} 
$5 \%$. Isso indica uma baixa taxa de substituição do $\mathrm{C}$ nativo pelo $\mathrm{C}$ derivado do eucalipto, com uma média anual de 0,25 \%. Assim, a substituição da vegetação nativa do Cerrado por eucalipto não resultou na diminuição do estoque de $\mathbf{C}$ nas frações FAH, FAF, MOL e BMS da MOS.

Termos de indexação: substâncias húmicas, biomassa microbiana, matéria orgânica leve.

\title{
SUMMARY: CARBON AND NITROGEN POOLS IN SOIL ORGANIC MATTER UNDER EUCALYPT, PASTURE AND SAVANNA VEGETATION IN BRAZIL
}

\begin{abstract}
The substitution of the native Cerrado (Brazilian savanna) vegetation by planted eucalyptus forests can influence the $C$ and $N$ pools in the different soil organic matter (SOM) fractions. However, the intensity and direction of this change depend on the soil type, climate, and management techniques in the planted area. The objective of this study was to determine the effect of eucalypt plantations on the C and N pool of labile and stable SOM fractions in an area previously occupied with savanna-like vegetation in the Vale do Jequitinhonha, $M G$, Brazil. Soil samples were collected from Eucalyptus urophylla plantations and adjacent areas with natural savanna vegetation, and managed pasture. The eucalypt plantation was 20-year old, and had succeeded the savanna vegetation, which was cut, the firewood removed and the residues burned. The pasture had been planted about 15 years earlier using the same site preparation procedures. There were no differences in total organic carbon (TOC) among soil samples of the three vegetation types. In the humic acid (HA) and fulvic acid (FA) fractions, the $C$ contents were about 16.6 and $17.5 \%$ higher for the eucalypt soil in comparison with the soils from the pasture and, 17.5 and $36.9 \%$ higher than in soils from the savanna, respectively. Replacing the savanna vegetation by eucalypt did not reduce the $C$ and $N$ pools of the soil microbial biomass of the soil, but increased the amounts of $C$ and $N$ in the light organic matter (LOM), contributing to an increase in SOM. The estimated contribution of $C$ derived from eucalypt to SOM based on ${ }^{13} \mathrm{C}$ natural abundance was $5 \%$. This indicates a low substitution rate of native $C$ by $C$ derived from eucalypt, with an mean annual rate of $0.25 \%$. It can be concluded that substituting the native savanna vegetation by eucalypt did not reduce the $C$ pools in the different SOM fractions.
\end{abstract}

Index terms: humic substances, microbial biomass, light organic matter, ${ }^{13} \mathrm{C}$ natural abundance.

\section{INTRODUÇÃO}

O carbono (C) acumula-se na atmosfera à taxa de $3,5 \mathrm{Pg}_{\text {ano }}^{-1}$, sendo a maior proporção resultante da queima de petróleo e carvão e da conversão de florestas tropicais para áreas de produção agrícola (Paustian et al., 2000). A concentração atual de dióxido de carbono $\left(\mathrm{CO}_{2}\right)$ na atmosfera é de $382 \mu \mathrm{mol} \mathrm{mol}^{-1}$ (Millard et al., 2007). O cultivo de florestas, principalmente nas regiões tropicais, tem sido apontado como meio eficiente no sequestro de $\mathrm{C} \mathrm{em}$ razão da acumulação deste na madeira e aumento do estoque no solo. Há, contudo, poucas informações sobre a efetividade das plantações florestais nos trópicos na retirada do $\mathrm{CO}_{2}$ da atmosfera, e por quanto tempo ele é mantido no ecossistema. Vários fatores, como clima, solo e condições socioeconômicas, interferem nesses processos (Albrecht \& Kandji, 2003).
As mudanças do carbono orgânico total (COT) em solos agrícolas em diversas regiões brasileiras demonstraram que as perdas médias de COT sob sistemas intensivos e não intensivos são pequenas em comparação com resultados obtidos em ecossistemas temperados. Isso pode ser em razão dos baixos estoques de COT na superfície, quando comparados com os solos de regiões temperadas, e da forte interação dos óxidos de $\mathrm{Fe}$ e $\mathrm{Al}$ da fração argila com a matéria orgânica do solo (MOS) (Zinn et al., 2005). Roscoe et al. (2001) constataram que, após 23 anos de cultivo de pastagem em substituição ao Cerrado, os teores de COT nos primeiros $100 \mathrm{~cm}$ de profundidade do solo não demonstraram diferenças significativas. Isso foi atribuído à alta produção de biomassa das pastagens tropicais e, especialmente, ao efeito protetor da MOS pela argila desses solos. Neufeldt et al. (2002) também constataram grande aumento na concentração de COT em solos sob pastagem comparados com solos sob 
vegetação nativa de Cerrado. Wilcke \& Lilienfein (2004) constataram que, após 20 anos do plantio de Pinus caribaea em solos argilosos anteriormente ocupados por vegetação de Cerrado, em Uberlândia $\mathrm{MG}$, houve o restabelecimento do teor de $\mathrm{C}$ na superfície $(0-30 \mathrm{~cm})$, enquanto que o $\mathrm{C}$ na camada mais inferior (30-200 cm) não foi afetado pela mudança do uso do solo. De modo geral, na região de Cerrado, as pastagens promovem a manutenção dos estoques de MOS e aquelas submetidas a boas práticas de manejo, às vezes, permitem a estocagem de $\mathrm{C}$ no solo superior ao observado sob a vegetação nativa (Roscoe et al., 2006).

No Brasil, a maior área de florestas plantadas é constituída pelo eucalipto, que, além do suprimento de madeira, contribui para o sequestro de $\mathrm{CO}_{2}$ da atmosfera. Todavia, há pouca informação sobre a taxa de acumulação e sobre a dinâmica da MOS nos solos sob cultivo de eucalipto no Brasil e como elas se comparam com outros sistemas de uso da terra. E provável que o estoque de $\mathrm{C}$ do solo das formações vegetais se relacione positivamente com sua produtividade primária. A redução da MOS pode comprometer a sustentabilidade da produção florestal em razão de seu efeito em processos relacionados à disponibilidade de água e de nutrientes para as plantas (Nambiar, 1999). Lima et al. (2008), estudando as frações de MOS após três décadas de cultivo de eucalipto no Vale do Jequitinhonha, constataram que o C da biomassa microbiana e da fração leve oclusa foram indicadores pouco sensíveis de mudanças na MOS após a implantação do eucalipto. Assim, o COT e as frações leve livre, ácido fúlvico, ácido húmico e humina foram mais eficientes nesse sentido.

Grande parte dos plantios de eucalipto no Brasil tem sido realizada na região de Cerrados, em substituição à vegetação natural ou a outros usos de terra, particularmente as pastagens. Contudo, pouco se sabe sobre as alterações na MOS que essa prática causa. Por isso, este trabalho objetivou determinar o efeito do plantio de eucalipto nos estoques de $\mathrm{C} \mathrm{e} \mathrm{N}$ em frações lábeis e estáveis da MOS em região de Cerrado no Vale do Jequitinhonha - MG.

\section{MATERIAL E MÉTODOS}

O estudo foi desenvolvido no município de Itamarandiba, no Vale do Jequitinhonha- MG, em solos sob povoamentos de Eucalyptus urophylla com 20 anos de idade, com espaçamento de $3 \times 2 \mathrm{~m}$, implantado após a derrubada, enleiramento e queima do Cerrado nativo. O mesmo sistema de preparo da área foi utilizado na implantação da pastagem. Para comparação, foram amostrados solos em áreas de pastagem e de Cerrado adjacentes. Além do estrato arbóreo, o componente mais importante do Cerrado sensu stricto é a camada rasteira que inclui principalmente gramíneas (Haridasan, 2000).
O solo das áreas amostradas foi classificado, segundo Sistema Brasileiro de Classificação, como Latossolo Vermelho-Amarelo muito argiloso, com topografia plana a suavemente ondulada. O clima é do tipo Cwa, pela classificação de Köppen, com a temperatura média anual de $20{ }^{\circ} \mathrm{C}$, sendo a temperatura média máxima anual de $26{ }^{\circ} \mathrm{C}$ e a temperatura média mínima de $15{ }^{\circ} \mathrm{C}$. A precipitação pluvial média anual é de $1.160 \mathrm{~mm}$, concentrada entre os meses de outubro e março, sendo os verões quentes e chuvosos e os invernos amenos e secos (Figura 1). A altitude é de $1.100 \mathrm{~m}$. Os dados climáticos correspondentes ao período do experimento foram obtidos em estações meteorológicas da AcelorMittal Jequitinhonha, localizada nas proximidades.

As amostras de solo foram coletadas em quatro parcelas de $600 \mathrm{~m}^{2}$, alocadas em áreas com eucalipto, pastagem e Cerrado, mas que originalmente eram cobertas com vegetação da tipologia Cerrado (Goodland $\&$ Ferri, 1979). Foram coletadas amostras compostas de solos em trincheiras, formadas por quatro amostras simples, nas profundidades de $0-10,10-20,20-40$, $40-60$ e $60-100 \mathrm{~cm}$. Em cada uma das quatro parcelas, nas mesmas profundidades, foram coletadas amostras indeformadas com anéis volumétricos para determinar a densidade do solo.

A amostragem do material vegetal acumulado sobre o solo foi realizada utilizando-se um gabarito de $0,25 \mathrm{~m}^{2}$, em quatro repetições, para as três coberturas vegetais; para o Cerrado e eucalipto foram coletadas folhas, galhos finos e grossos à superfície do solo; para a pastagem foram coletadas folhas mortas sobre a superfície do solo.

Esses materiais foram acondicionados em sacos plásticos e transportados para o laboratório. Posteriormente, foi realizada a separação das folhas, galhos finos e grossos da serapilheira, antes da secagem em estufa a $72{ }^{\circ} \mathrm{C}$ por cinco dias para, então, se fazer a determinação da massa seca. As amostras foram trituradas em moinho tipo Wiley e, então, submetidas à digestão nítrico-perclórica para a determinação dos teores de $\mathrm{K}$ (fotometria de chama), de $\mathrm{P}$ (colorimetria, pelo método da vitamina $\mathrm{C}$, modificado por Braga \& Defelipo, 1974), $\mathrm{Ca}, \mathrm{Mg}, \mathrm{Cu}$, e

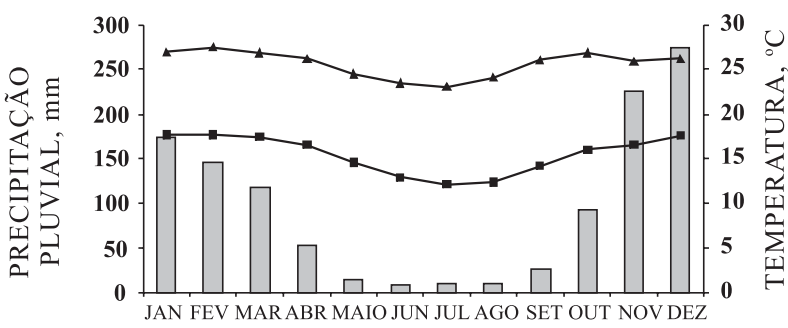

Figura 1. Variação da média mensal de precipitação pluvial e temperatura ( $\Delta$ : máxima; $\square$ : mínima) em Itamarandiba - MG, durante o período de 1988 a 2004. 
Zn (espectroscopia de absorção atômica). A análise do $\mathrm{N}$ e $\mathrm{C}$ total foi realizada por combustão a seco em analisador elementar CHNS/0 2400 (Perkin Elmer). As amostras de solo foram secas ao ar, passadas em peneira com malha de $2 \mathrm{~mm}$, e submetidas à análise química (Embrapa, 1997). A análise granulométrica foi realizada pelo método da pipeta (Quadro 1).

O carbono orgânico total do solo (COT) foi determinado a partir de amostras de TFSA trituradas em almofariz, passadas em peneira de 0,5 mm e submetidas à determinação do teor de carbono orgânico (CO) por oxidação úmida, com aquecimento externo (Yeomans \& Bremner, 1988). O nitrogênio total (NT) foi determinado utilizando o método Kjeldahl, modificado por Tedesco (1985). A matéria orgânica leve (MOL), fracionada fisicamente, foi separada conforme método proposto por Sohi et al. (2001) utilizando-se solução de $\mathrm{NaI}\left(1,8 \mathrm{~kg} \mathrm{~L}^{-1}\right)$. A fração orgânica sobrenadante na solução (fração leve livre) foi lavada extensivamente com água destilada, visando eliminar o excesso de NaI. Em seguida, essa fração foi seca a, aproximadamente, $65^{\circ} \mathrm{C}$, pesada e macerada em almofariz. Os teores de CO da matéria orgânica leve (MOL) foram determinados por combustão via seca em analisador elementar (Perkin Elmer CHNS/ O 2400).

As substâncias húmicas (SH) foram extraídas de amostras de TFSA. Após serem maceradas e passadas em peneira de 100 mesh $(0,149 \mathrm{~mm})$, as amostras foram submetidas ao fracionamento segundo o método da International Humic Substances Society (IHSS) (Swift, 1996). Foram obtidas as frações correspondentes aos ácidos fúlvicos (FAF), ácidos húmicos (FAH) e humina $(\mathrm{FH})$, com base na solubilidade diferencial em soluções alcalinas e ácidas. Do somatório de todas essas frações húmicas foram obtidas as substâncias húmicas. A determinação do $\mathrm{C}$ de cada fração húmica foi realizada pelo método de oxidação úmida, com aquecimento externo (Yeomans \& Bremner, 1988).
Para a determinação de $\mathrm{N}$ total nas substâncias húmicas, foi utilizado o método Kjeldahl (Tedesco, 1985).

$\mathrm{O} \mathrm{C}$ e $\mathrm{N}$ da biomassa microbiana (C-BM e N-BM) foram determinados a partir de amostras de solo acondicionadas em frascos plásticos com tampas perfuradas, que foram incubados por 16 dias, a $25^{\circ} \mathrm{C}$, com a umidade correspondente a $80 \%$ do equivalente de umidade $(-33 \mathrm{kPa})$, para permitir o restabelecimento da comunidade microbiana. A umidade das amostras foi aferida a cada dois dias. Findo o período de incubação, foram determinados os teores de C-BM e N-BM pelo método da irradiaçãoextração (Islam \& Weil, 1998), utilizando forno microondas com potência de $900 \mathrm{~W}$ e frequência de $2.450 \mathrm{MHz}$. Após a irradiação, as amostras foram submetidas ao extrator $\mathrm{K}_{2} \mathrm{SO}_{4} 0,5 \mathrm{~mol} \mathrm{~L}-1$. O C nos extratos foi quantificado por meio de oxidação úmida, sem aquecimento externo. $\mathrm{O}$ fator de conversão $\left(\mathrm{K}_{\mathrm{C}}\right)$ usado para converter o $\mathrm{C}$ determinado para $\mathrm{C}$ da biomassa microbiana foi de 0,33 (Sparling \& West, 1988). O N contido no extrato foi quantificado por meio de digestão sulfúrica, seguida da destilação e titulação com solução de $\mathrm{HCl}$ (Tedesco, 1985). O fator de conversão $\left(\mathrm{K}_{\mathrm{N}}\right)$ utilizado para converter o $\mathrm{N}$ determinado em N-BM foi de 0,54 (Brookes et al., 1985). Os teores de C-BM e N-BM foram expressos com base na massa de solo seco em estufa a $65^{\circ} \mathrm{C}$ por $48 \mathrm{~h}$.

Os resultados obtidos foram submetidos à análise de variância, e as médias, para cada profundidade, foram comparadas pelo teste LSD de Fisher, protegido (Steel et al., 1997). Essas análises foram realizadas com o programa estatístico SAEG 5.0 (Funarbe, 1993). Os estoques de $\mathrm{C}$ e $\mathrm{N}$ das diferentes frações da MOS, nas diferentes camadas do solo, foram calculados multiplicando-se o teor de $\mathrm{C}$ ou $\mathrm{N}$ pelo volume de solo em cada camada de solo e pela densidade do solo sob Cerrado nas diferentes profundidades. Tal procedimento evita que o aumento da densidade do solo,

Quadro 1. Características químicas e físicas de amostras de um Latossolo Vermelho-Amarelo, coletadas na profundidade de 0-20 cm sob Cerrado, pastagem e Eucalyptus urophylla

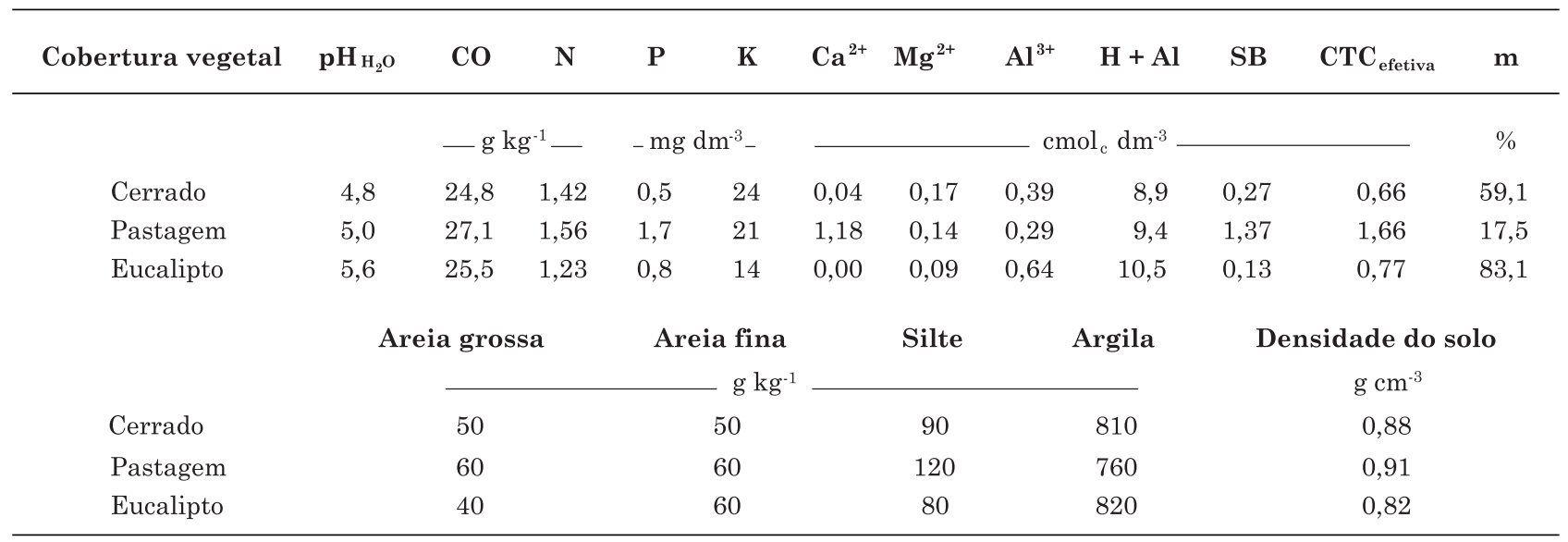


induzido pelo manejo nas áreas cultivadas, resulte em maiores estoques de C. O delineamento experimental foi em blocos ao acaso, com parcelas subdivididas. $\mathrm{O}$ uso do solo (Cerrado, pastagem, eucalipto) foi considerado como a parcela principal, enquanto as profundidades de amostragem foram consideradas como subparcelas.

Para a análise da abundância natural do ${ }^{13} \mathrm{C}$, as amostras de solo da camada de $0-10 \mathrm{~cm}$ foram passadas em peneira de 100 mesh $(0,149 \mathrm{~mm})$ e a relação ${ }^{13} \mathrm{C} /{ }^{12} \mathrm{C}$ foi medida em espectrômetro de massa de razão isotópica de fluxo contínuo (20-20 Anca-GLS, Sercon, Crewe, UK). A razão isotópica foi expressa em partes por $1.000 \%$, em relação ao padrão de Pee Dee Belemnita (PDB). O compartimento de $\mathrm{C}$ derivado da pastagem $\left(\mathrm{C}_{4}\right)$ foi calculado conforme Vitorello et al. (1989):

$$
\% C_{4}=\left(\frac{\delta-\delta_{s}}{\delta_{p}-\delta_{s}}\right)
$$

em que $\delta$ é a abundância natural do ${ }^{13} \mathrm{C}$ nas amostras de solo, $\delta_{\mathrm{s}}$ é abundância natural do ${ }^{13} \mathrm{C}$ nas amostras de solos sem nenhuma contribuição das plantas $\mathrm{C}_{4}$; $\delta_{\mathrm{p}}$ é abundância natural do ${ }^{13} \mathrm{C}$ nas amostras das plantas $\mathrm{C}_{4}$ (pastagem). Os valores de $\delta_{\mathrm{s} \text { e }} \delta_{\mathrm{p}}$ foram determinados, respectivamente, em seis amostras de solo coletadas sob floresta nativa nas proximidades dos povoamentos de eucalipto e amostras de material vegetal proveniente da pastagem. A contribuição percentual do $\mathrm{C}$ orgânico originário da planta $\mathrm{C}_{3}$ (eucalipto, incluindo o $\mathrm{C}$ antigo do período em que $\mathrm{o}$ solo esteve coberto com floresta) foi calculada como $\% C_{3}=100-\% C_{4}$.

\section{RESULTADOS E DISCUSSÃO}

\section{Teor e estoque de $\mathrm{C}$ e $\mathrm{N}$ na serapilheira}

A quantidade de matéria seca da serapilheira do eucalipto foi superior $(\mathrm{p}<0,05)$ à do Cerrado e da pastagem (Quadro 2), possivelmente em razão da pobreza nutricional dos resíduos do eucalipto (Quadro 3), especialmente em P e K, em comparação aos demais materiais vegetais e à participação de galhos finos e grossos na serapilheira dessa cobertura vegetal, materiais com baixa concentração de nutrientes. Essa pobreza da serapilheira de eucalipto tem sido atribuída à sua eficiente ciclagem bioquímica (Gama-Rodrigues \& Barros, 2002). Baixos teores de nutrientes no material vegetal, geralmente, correlacionam-se com baixas taxas de decomposição (Cobo et al., 2002). Também, os materiais com elevada relação $\mathrm{C} / \mathrm{N}$ (> 25) e altos teores de lignina e polifenóis sofrem decomposição mais lenta (Myers et al., 1994). Estudos mostram que, quando os componentes de planta são mais lignificados e aromáticos, se decompõem mais lentamente, favorecendo a manutenção de substâncias orgânicas no solo (Gosz, 1984; Kuzyakov \& Domanski, 2000). A serapilheira de eucalipto apresenta alta relação $\mathrm{C} / \mathrm{N}$, de 30 a 100, de acordo com a parte da planta estudada, e também alta relação $\mathrm{C} / \mathrm{P}$ e $\mathrm{C} / \mathrm{S}$, o que contribui para lenta decomposição do resíduo (Adams \& Attiwill, 1986; Louzada et al., 1997; Skorupa, 2001). Esses fatores contribuem para os incrementos nos estoques de COT e NT, principalmente nas camadas mais superficiais. A quantidade de serapilheira do eucalipto na região estudada foi considerada baixa, cerca de 13,8 $\mathrm{t} \mathrm{ha}^{-1}$, quando comparada com a observada em outras regiões, podendo chegar a 18,1 t ha-1 (Kolm \& Poggiani, 2003; Martins et al., 1995). A vegetação nativa de Cerrado da região estudada apresenta baixa densidade populacional, com baixa produtividade primária líquida e, assim, baixos valores de massa para serapilheira, cerca de 4,04 tha-1 (Quadro 2). Vieira (1998), em Itatinga (SP), encontrou $11 \mathrm{t} \mathrm{ha}^{-1}$ de serapilheira acumulada sob vegetação natural de Cerrado.

\section{Teor e estoque de $\mathrm{C}$ e $\mathrm{N}$ no solo e nas substâncias húmicas}

Não houve diferença significativa para os teores de COT no solo entre as coberturas vegetais estudadas nas diferentes profundidades, embora houvesse diminuição do teor do COT com o aumento da profundidade (Figura 2). Isso indica que a substituição de Cerrado por pastagem e eucalipto não resultou em decréscimo do COT, ou que o aporte por estas duas coberturas foi semelhante àquele de Cerrado. Os teores de NT foram maiores no solo sob pastagem e menores naquele cultivado com eucalipto nas camadas de 0 10 e 10-20 cm de profundidade (Figura 3). A relação $\mathrm{C} / \mathrm{N}$ foi maior para o solo sob eucalipto (em torno de $22: 1$ ), ao passo que o solo das outras coberturas apresentou relação $\mathrm{C} / \mathrm{N}$ menor que 20 (Figura 2).

Os maiores teores de $\mathrm{C}$ nos solos sob as diferentes coberturas vegetais estudadas foram encontrados na fração humina (FH), e aquele cultivado com eucalipto apresentou o menor valor (12,1 $\left.\mathrm{g} \mathrm{kg}^{-1}\right)$ em comparação com aqueles de outras coberturas. Estudos em solos sob clima tropical apresentaram resultados similares

Quadro 2. Estoque de C e de N (t ha-1) e quantidade de matéria seca $\left(\mathrm{t} \mathrm{ha}^{-1}\right)$ da serapilheira sob Cerrado, pastagem e eucalipto. Colunas seguidas por letras iguais não diferem entre $s i(p>0,05)$ pelo teste LSD de Fisher protegido

\begin{tabular}{lccc}
\hline & Estoque de C & Estoque de N & Massa \\
\cline { 2 - 4 } & & $\mathrm{t} \mathrm{ha}^{-1}$ & \\
Cerrado & $1,13 \mathrm{~b}$ & $0,019 \mathrm{~b}$ & $4,04 \mathrm{~b}$ \\
Pastagem & $1,10 \mathrm{~b}$ & $0,026 \mathrm{~b}$ & $2,69 \mathrm{~b}$ \\
Eucalipto & $3,62 \mathrm{a}$ & $0,040 \mathrm{a}$ & $7,42 \mathrm{a}$ \\
\hline
\end{tabular}


Quadro 3. Características químicas da camada L (folha, galho fino e galho grosso) sob Cerrado (três repetições para folhas e uma para galhos), pastagem e Eucalyptus urophylla

\begin{tabular}{|c|c|c|c|c|c|c|c|c|c|c|c|}
\hline $\begin{array}{l}\text { Cobertura } \\
\text { vegetal }\end{array}$ & $\begin{array}{l}\text { Frações da } \\
\text { serapilheira }\end{array}$ & $\mathbf{N}$ & $\mathbf{C}$ & $\mathbf{K}$ & $\mathbf{P}$ & $\mathbf{M g}^{2+}$ & $\mathrm{Ca}^{2+}$ & $\mathrm{C} / \mathrm{N}$ & $\mathrm{Zn}$ & $\mathrm{Cu}$ & Massa \\
\hline & & & & - & $\mathrm{g}^{-1}$ & & - & & $-\mathrm{mg}$ & -1 & $\mathrm{t} \mathrm{ha}^{-1}$ \\
\hline Cerrado & $\begin{array}{l}\text { Folha } \\
\text { Galho fino } \\
\text { Galho grosso }\end{array}$ & $\begin{array}{l}9,3 \mathrm{a} \\
7,5 \\
7,5\end{array}$ & $\begin{array}{l}504 \mathrm{a} \\
490 \\
479\end{array}$ & $\begin{array}{l}2,31 \mathrm{a} \\
2,98 \\
2,08\end{array}$ & $\begin{array}{l}0,43 \mathrm{a} \\
0,34 \\
0,26\end{array}$ & $\begin{array}{l}2,5 \mathrm{a} \\
1,6 \\
1,8\end{array}$ & $\begin{array}{l}4,8 \mathrm{a} \\
4,7 \\
5,2\end{array}$ & $\begin{array}{l}54 \mathrm{a} \\
65 \\
64\end{array}$ & $\begin{array}{l}8,6 \mathrm{~b} \\
14,4 \\
14,6\end{array}$ & $\begin{array}{l}3,4 \mathrm{a} \\
7,7 \\
7,2\end{array}$ & $\begin{array}{l}2,24 \mathrm{a} \\
1,10 \\
0,70\end{array}$ \\
\hline Pastagem & Folha & $9,7 \mathrm{a}$ & $408 \mathrm{c}$ & $2,60 \mathrm{a}$ & $0,48 \mathrm{a}$ & $1,7 \mathrm{a}$ & $5,5 \mathrm{a}$ & $42 \mathrm{a}$ & $17,0 \mathrm{a}$ & $4,6 \mathrm{a}$ & $2,69 \mathrm{a}$ \\
\hline Eucalipto & $\begin{array}{l}\text { Folha } \\
\text { Galho fino } \\
\text { Galho grosso }\end{array}$ & $\begin{array}{l}8,6 \text { a } \\
3,4 \\
3,7\end{array}$ & $\begin{array}{l}484 \mathrm{~b} \\
494 \\
487\end{array}$ & $\begin{array}{l}0,36 \mathrm{~b} \\
0,26 \\
0,11\end{array}$ & $\begin{array}{l}0,27 b \\
0,15 \\
0,16\end{array}$ & $\begin{array}{l}1,1 \mathrm{a} \\
0,7 \\
0,3\end{array}$ & $\begin{array}{l}2,4 \mathrm{a} \\
1,5 \\
0,4\end{array}$ & $\begin{array}{l}56 \mathrm{a} \\
145 \\
131\end{array}$ & $\begin{array}{l}5,6 \mathrm{~b} \\
5,0 \\
3,0\end{array}$ & $\begin{array}{l}3,3 \mathrm{a} \\
3,0 \\
2,2\end{array}$ & $\begin{array}{l}2,79 \mathrm{a} \\
2,04 \\
2,59\end{array}$ \\
\hline
\end{tabular}

Para as folhas, médias seguidas pela mesma letra na coluna não diferem entre si $(p>0,05)$ pelo teste de LSD de Fisher protegido.
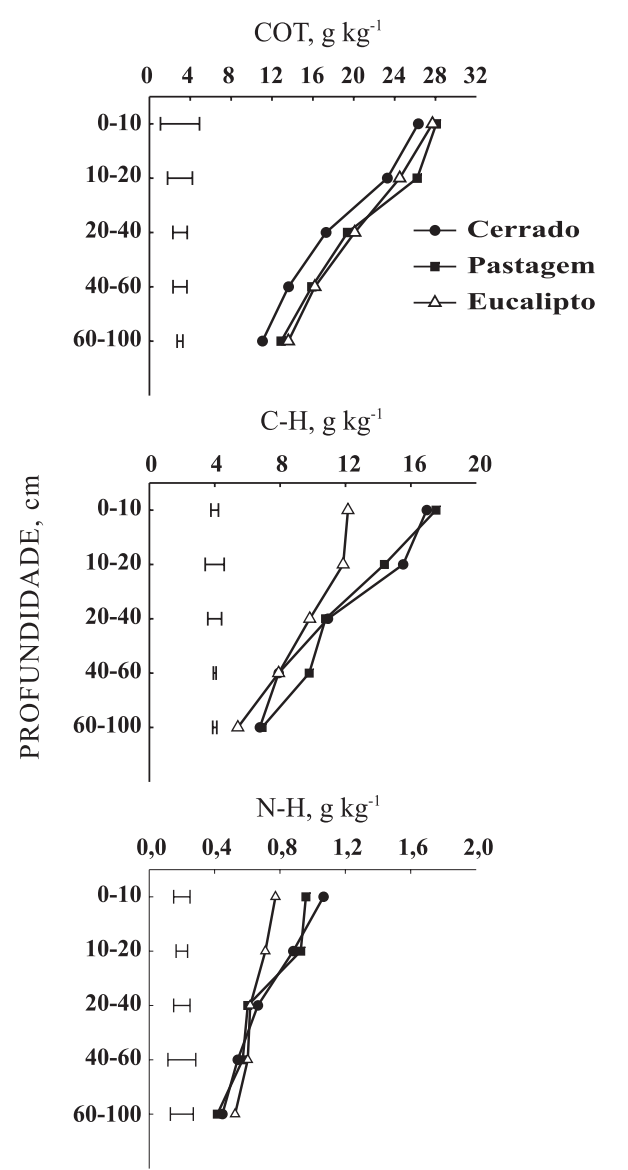

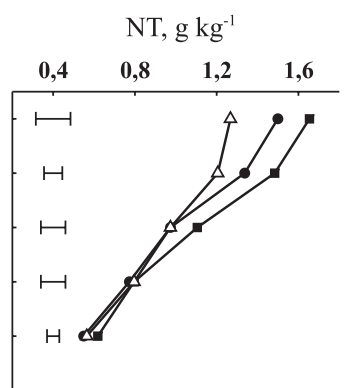

C-AH, $\mathrm{g} \mathrm{kg}^{-1}$
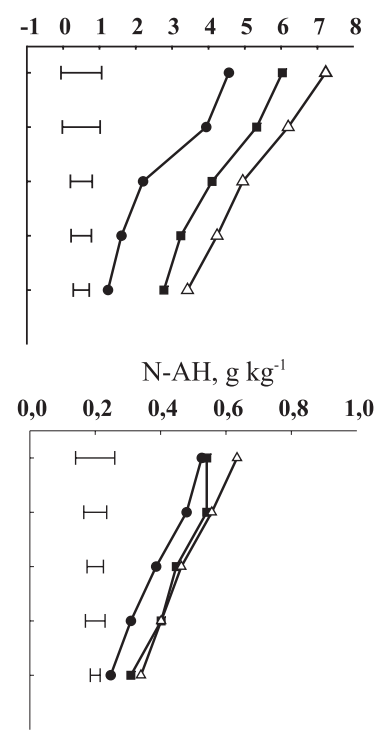

RELAÇÃO C/N

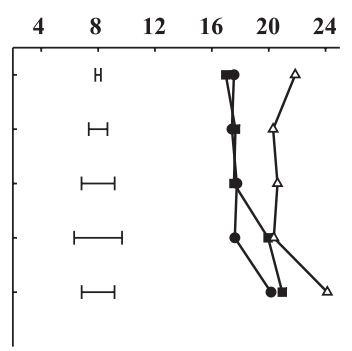

C-AF, $\mathrm{g} \mathrm{kg}^{-1}$
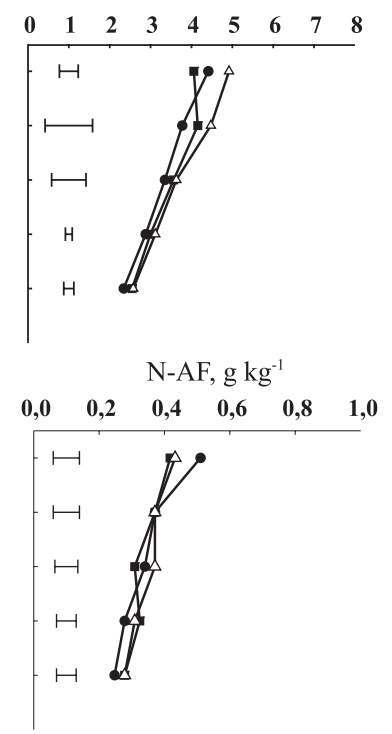

Figura 2. Teores de carbono orgânico total (COT) e nitrogênio total (NT) do solo e das frações humina (H), ácidos húmicos (AH) e ácidos fúlvicos (AF) nas diferentes coberturas vegetais (Cerrado, pastagem e eucalipto). As barras horizontais indicam a DMS (5\%), entre as médias, de acordo com a camada de solo.

quanto ao maior teor de $\mathrm{C}$ na FH (Mendonça, 1988; Coelho, 1991; Leite, 2002). Este fato pode ser atribuído à interação da matéria orgânica com a fração mineral desse solo que é muito argiloso. No entanto, nas frações ácido húmico e ácido fúlvico (FAH e FAF), os teores de $\mathrm{C}$ foram cerca de 16,6 e 17,5 \% maiores para o eucalipto quando comparados com a pastagem, e 17,5 e $36,9 \%$ em relação ao solo sob Cerrado, respectivamente (Figura 2 ). $\mathrm{O}$ maior estoque de $\mathrm{C}$ na FAH e FAF do solo sob eucalipto deve-se, provavelmente, à maior produção de resíduos vegetais dessa cultura, que os repõe via decomposição mais lenta. 


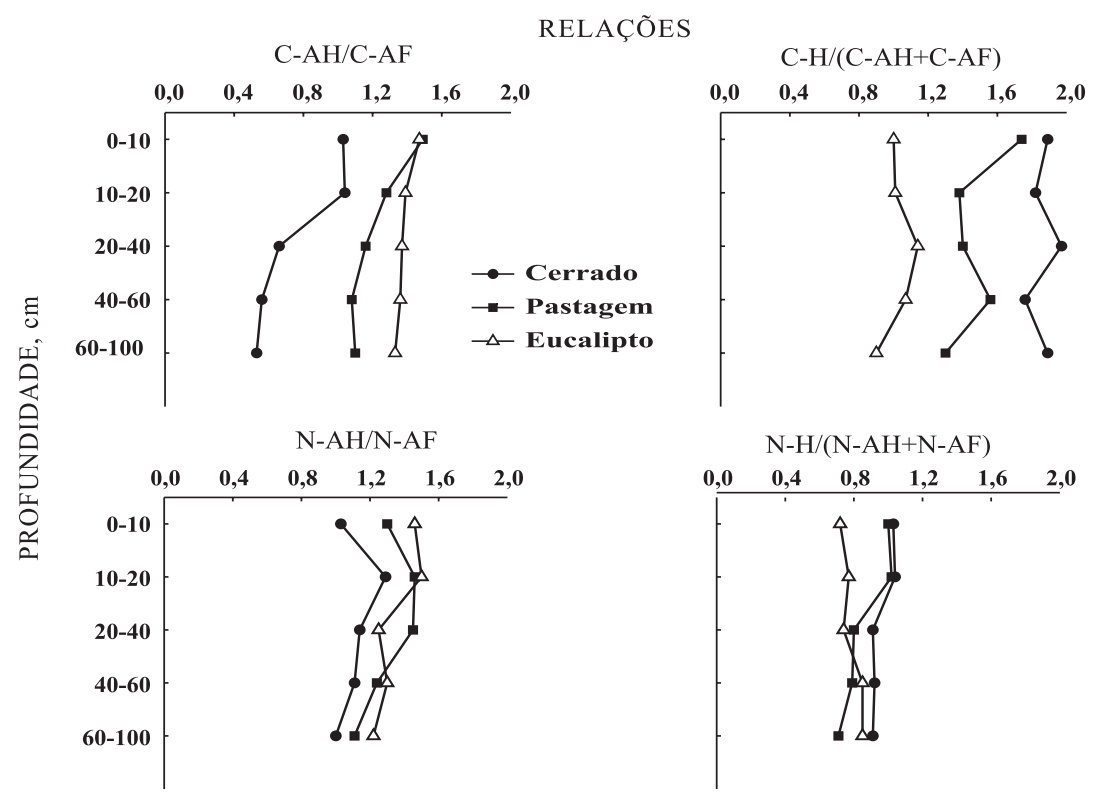

Figura 3. Relações de carbono orgânico total (COT) e nitrogênio total (NT) das frações humina, ácidos húmicos (AH) e ácidos fúlvicos (AF) nos solos sob diferentes coberturas vegetais (Cerrado, pastagem e eucalipto).

As três coberturas vegetais estudadas apresentaram diferenças significativas $(p<0,05)$ nas camadas superficiais para os teores de NT nas FAF e FH, e o solo sob vegetação nativa de Cerrado apresentou os maiores valores de NT para todas as frações, exceto FAH. A FH apresentou os maiores valores de NT em todas coberturas vegetais estudadas (Figura 2). A relação C-AH/C-AF foi menor para o solo sob Cerrado (Figura 3) em todas as profundidades estudadas, em comparação com o solo cultivado com pastagem e com eucalipto, ficando abaixo de 1,0 nas maiores profundidades. O cultivo de eucalipto ou de pastagem em área de Cerrado levou ao aumento do C-AH. A maior proporção dos ácidos húmicos sugere melhoria da qualidade do húmus ou aumento da atividade biológica (Orlov, 1998; Canellas et al., 2007). No entanto, a relação N-AH/N-AF foi menor para o solo de pastagem (Figura 3). A relação C-AH/C-AF tendeu a diminuir com a profundidade para as diferentes coberturas vegetais, e foi superior a 1,0 para o solo sob pastagem e eucalipto.

A retirada da vegetação nativa para introdução de pastagens leva a importantes modificações na dinâmica das substâncias húmicas. Neste estudo, foi observado que, para o solo sob Cerrado ou cultivado com pastagem, cerca de mais de $60 \%$ do COT foi proveniente da $\mathrm{FH}$ e para o solo cultivado com eucalipto cerca de $50 \%$ do COT foi proveniente da FH, seguidas das frações FAH e FAF. A influência da pastagem nas frações húmicas de Latossolos distróficos sob Cerrado e da floresta Amazônica foi estudada por Longo \& Espíndola (2000), que constataram diminuição dos estoques das FAF, FAH e FH, decorrente da mudança da vegetação natural para outros usos, evidenciando o efeito do manejo sobre o teor e sobre a distribuição dos componentes orgânicos em solos tropicais. Verificou-se menor relação $\mathrm{C}-\mathrm{H} /$ (C-AH + C-AF) no solo de eucalipto em comparação com as outras coberturas em todas as profundidades estudadas (Figura 3).

Os cultivos do eucalipto e da pastagem aumentaram os estoques de COT no solo na camada de $0-100 \mathrm{~cm}$ de profundidade em relação ao Cerrado. Isso se deve provavelmente ao sistema radicular de ciclagem rápida da pastagem e à maior produção de serapilheira no eucalipto (Quadro 2). Os estoques de $\mathrm{N}$ até $1 \mathrm{~m}$ de profundidade também foram maiores para solo sob pastagem, enquanto não houve diferenças significativas entre os solos sob eucalipto e aqueles de Cerrado. Ao contrário do observado para o estoque de COT, as maiores diferenças para os estoques de NT entre o solo das coberturas ocorreram na camada de 0-10 $\mathrm{cm}$ de profundidade (Quadro 4).

Os dados demonstram que, no solo em que a pastagem substituiu o Cerrado, houve aumento dos estoques de COT e NT na camada de até $100 \mathrm{~cm}$ de profundidade (Quadro 4). Da mesma forma, a substituição da vegetação de Cerrado no Vale do Jequitinhonha pelo eucalipto não resultou em redução do estoque de COT do solo, mas sim em aumento de $13 \%$ na camada de $0-100 \mathrm{~cm}$. Contudo, observou-se a diminuição do estoque de NT em $15 \%$ na camada de $0-10 \mathrm{~cm}, 10 \%$ na camada de $10-20 \mathrm{~cm}$ e $3 \%$ na camada de $0-100 \mathrm{~cm}$. A maior parte do $\mathrm{N}$ no solo apresenta-se ligada a compostos orgânicos. Portanto, modificações na MOS alteram significativamente os teores deste elemento no solo (Whiethölter, 2000). Bird et al. (2003), estudando a estabilização de ${ }^{13} \mathrm{C}$-carbono e imobilização do ${ }^{15} \mathrm{~N}$-Nitrogênio nas frações húmicas 
da palhada de arroz, constataram que há divergência nas vias de humificação do $\mathrm{C}$ e $\mathrm{N}$ nos subprodutos da palhada. A maior parte do ${ }^{13} \mathrm{C}$ da palhada ficou na fração humina enquanto a maior parte do ${ }^{15} \mathrm{~N}$ foi estabilizada como ácido húmico móvel na palhada. Neufeldt et al. (2002) também constataram grande aumento na concentração de COT em solos cultivados com pastagem comparados com solos sob vegetação nativa de Cerrado. De modo geral, a literatura científica parece indicar que, na região de Cerrado, as pastagens promovem a manutenção dos estoques de MOS, e que pastagens submetidas a boas práticas de manejo, às vezes, permitem a estocagem de $\mathrm{C}$ no solo superior ao observado sob a vegetação nativa (Roscoe et al., 2006).

As camadas mais profundas dos solos sob Cerrado, pastagem e eucalipto apresentaram menor diferença na FH (Quadro 5), possivelmente por esta fração apresentar maior recalcitrância, além da sua íntima associação com as frações texturais mais finas do solo.

$\mathrm{O}$ estoque de $\mathrm{C}$ na $\mathrm{FH}$ foi menor no solo sob eucalipto em comparação com o solo sob pastagem e Cerrado. No entanto, o estoque de $\mathrm{C}$ das FAH e FAF foi maior para o eucalipto, indicando a menor estabilidade do $\mathrm{C}$ no solo desta cobertura vegetal (Quadro 5). Isso pode ter ocorrido em razão dos baixos teores de Ca no solo e na serapilheira de eucalipto (Quadros 1 e 2). A remoção do Ca do solo estimula a decomposição da MOS e a mineralização do N (Gaiffe et al., 1984).

\section{Estoques de carbono e nitrogênio na matéria orgânica leve}

Os maiores estoques de $\mathrm{C}$ da matéria orgânica leve (C-MOL) encontram-se na camada mais superficial

Quadro 4. Estoques de carbono orgânico total (COT) e nitrogênio total (NT) nas diversas camadas de solo sob Cerrado, pastagem e eucalipto. Linhas seguidas por letras iguais, dentro de cada profundidade, não diferem entre $\operatorname{si}(p>0,05)$ pelo teste LSD de Fisher protegido

\begin{tabular}{crrr}
\hline Camada de solo & Cerrado & Pastagem & Eucalipto \\
\hline $\mathrm{cm}$ & \multicolumn{3}{c}{$\mathrm{t} \mathrm{ha}^{-1} \mathrm{COT}$} \\
\cline { 2 - 4 } $0-10$ & $22,39 \mathrm{a}$ & $23,88 \mathrm{a}$ & $23,57 \mathrm{a}$ \\
$10-20$ & $21,18 \mathrm{a}$ & $23,83 \mathrm{a}$ & $22,26 \mathrm{a}$ \\
$20-40$ & $30,69 \mathrm{~b}$ & $34,45 \mathrm{a}$ & $35,65 \mathrm{a}$ \\
$40-60$ & $22,63 \mathrm{~b}$ & $26,40 \mathrm{a}$ & $26,93 \mathrm{a}$ \\
$60-100$ & $35,80 \mathrm{~b}$ & $41,93 \mathrm{a}$ & $44,04 \mathrm{a}$ \\
$0-100$ & $132,69 \mathrm{~b}$ & $150,49 \mathrm{a}$ & $152,45 \mathrm{a}$ \\
& & $\mathrm{NT}$ & \\
$0-10$ & $1,27 \mathrm{a}$ & $1,41 \mathrm{a}$ & $1,08 \mathrm{~b}$ \\
$10-20$ & $1,22 \mathrm{a}$ & $1,35 \mathrm{a}$ & $1,10 \mathrm{a}$ \\
$20-40$ & $1,73 \mathrm{a}$ & $1,96 \mathrm{a}$ & $1,73 \mathrm{a}$ \\
$40-60$ & $1,28 \mathrm{a}$ & $1,32 \mathrm{a}$ & $1,32 \mathrm{a}$ \\
$60-100$ & $1,77 \mathrm{a}$ & $2,00 \mathrm{a}$ & $1,82 \mathrm{a}$ \\
$0-100$ & $7,27 \mathrm{~b}$ & $8,04 \mathrm{a}$ & $7,05 \mathrm{~b}$ \\
\hline
\end{tabular}

dos solos das três coberturas vegetais estudadas (Quadro 6). No solo sob cultivo de eucalipto, foram observados os maiores valores de C-MOL em comparação com os outros usos, sendo $58 \%$ superior ao solo do Cerrado na camada de $0-10 \mathrm{~cm}$ e $41 \%$ superior em comparação com a pastagem na camada de $0-100 \mathrm{~cm}$. O maior aporte de resíduos advindos do plantio de eucalipto deve ser responsável por essa superioridade. Roscoe et al. (2001) observaram elevada quantidade de C-MOL na camada de 0-7,5 cm em solos

Quadro 5. Estoques de carbono e nitrogênio nas frações humina, ácido húmico, ácido fúlvico em diversas camadas sob Cerrado, pastagem e eucalipto. Linhas seguidas por letras iguais, dentro de cada profundidade, não diferem entre si $(p>0,05)$ pelo teste LSD de Fisher protegido

\begin{tabular}{|c|c|c|c|}
\hline Camada de solo & Cerrado & Pastagem & Eucalipto \\
\hline \multirow[t]{2}{*}{$\mathrm{cm}$} & \multicolumn{3}{|c|}{$\mathrm{t} \mathrm{ha}^{-1}$} \\
\hline & \multicolumn{3}{|c|}{ C-Humina } \\
\hline $0-10$ & $14,42 \mathrm{a}$ & $14,92 \mathrm{a}$ & $10,33 \mathrm{~b}$ \\
\hline $10-20$ & $14,12 \mathrm{a}$ & $13,07 \mathrm{a}$ & $10,79 \mathrm{~b}$ \\
\hline $20-40$ & $19,40 \mathrm{a}$ & $19,14 \mathrm{a}$ & $17,42 \mathrm{a}$ \\
\hline $40-60$ & $13,14 \mathrm{a}$ & $16,25 \mathrm{a}$ & $13,14 \mathrm{a}$ \\
\hline $60-100$ & $21,87 \mathrm{a}$ & $22,33 \mathrm{a}$ & $17,53 \mathrm{~b}$ \\
\hline \multirow[t]{2}{*}{$0-100$} & 82,95 a & $85,71 \mathrm{a}$ & $69,21 \mathrm{~b}$ \\
\hline & \multicolumn{3}{|c|}{ C-Ácido húmico } \\
\hline $0-10$ & $3,88 \mathrm{c}$ & $5,13 \mathrm{~b}$ & $6,15 \mathrm{a}$ \\
\hline $10-20$ & $3,58 \mathrm{~b}$ & $4,85 \mathrm{a}$ & $5,63 \mathrm{a}$ \\
\hline $20-40$ & $3,90 \mathrm{c}$ & $7,28 \mathrm{~b}$ & $8,78 \mathrm{a}$ \\
\hline $40-60$ & $2,67 \mathrm{c}$ & $5,39 \mathrm{~b}$ & 7,04 a \\
\hline $60-100$ & $3,99 \mathrm{c}$ & $8,98 \mathrm{~b}$ & $11,08 \mathrm{a}$ \\
\hline \multirow[t]{2}{*}{$0-100$} & $18,02 \mathrm{c}$ & $31,63 \mathrm{~b}$ & $38,68 \mathrm{a}$ \\
\hline & \multicolumn{3}{|c|}{ C-Ácido fúlvico } \\
\hline $0-10$ & $3,75 \mathrm{~b}$ & $3,45 \mathrm{~b}$ & $4,18 \mathrm{a}$ \\
\hline $10-20$ & $3,43 \mathrm{a}$ & $3,78 \mathrm{a}$ & $4,07 \mathrm{a}$ \\
\hline $20-40$ & $5,95 \mathrm{a}$ & $6,33 \mathrm{a}$ & $6,45 \mathrm{a}$ \\
\hline $40-60$ & $4,79 \mathrm{a}$ & $4,98 \mathrm{a}$ & $5,18 \mathrm{a}$ \\
\hline $60-100$ & $7,59 \mathrm{a}$ & $8,25 \mathrm{a}$ & $8,34 \mathrm{a}$ \\
\hline \multirow[t]{2}{*}{$0-100$} & $25,51 \mathrm{c}$ & $26,79 \mathrm{~b}$ & $28,22 \mathrm{a}$ \\
\hline & \multicolumn{3}{|c|}{ N-Humina } \\
\hline $0-10$ & $0,91 \mathrm{a}$ & $0,81 \mathrm{a}$ & $0,66 \mathrm{~b}$ \\
\hline $10-20$ & $0,80 \mathrm{a}$ & $0,84 \mathrm{a}$ & $0,65 \mathrm{a}$ \\
\hline $20-40$ & $1,18 \mathrm{a}$ & $1,07 \mathrm{a}$ & $1,10 \mathrm{a}$ \\
\hline $40-60$ & $0,90 \mathrm{a}$ & $0,95 \mathrm{a}$ & $1,00 \mathrm{a}$ \\
\hline $60-100$ & $1,45 \mathrm{a}$ & $1,35 \mathrm{a}$ & $1,70 \mathrm{a}$ \\
\hline \multirow[t]{2}{*}{$0-100$} & $5,24 \mathrm{a}$ & $5,02 \mathrm{~b}$ & $5,11 \mathrm{ab}$ \\
\hline & \multicolumn{3}{|c|}{ N-Ácido húmico } \\
\hline $0-10$ & $0,45 \mathrm{a}$ & $0,46 \mathrm{a}$ & $0,54 \mathrm{a}$ \\
\hline $10-20$ & $0,44 \mathrm{a}$ & $0,49 \mathrm{a}$ & $0,51 \mathrm{a}$ \\
\hline $20-40$ & $0,69 \mathrm{~b}$ & $0,80 \mathrm{a}$ & $0,82 \mathrm{a}$ \\
\hline $40-60$ & $0,51 \mathrm{~b}$ & $0,67 \mathrm{a}$ & $0,67 \mathrm{a}$ \\
\hline $60-100$ & $0,80 \mathrm{~b}$ & $1,00 \mathrm{a}$ & $1,10 \mathrm{a}$ \\
\hline \multirow[t]{2}{*}{$0-100$} & $2,89 \mathrm{~b}$ & $3,42 \mathrm{a}$ & 3,64 a \\
\hline & \multicolumn{3}{|c|}{ N-Ácido fúlvico } \\
\hline $0-10$ & $0,43 \mathrm{a}$ & $0,35 \mathrm{a}$ & $0,37 \mathrm{a}$ \\
\hline $10-20$ & $0,34 \mathrm{a}$ & $0,34 \mathrm{a}$ & $0,34 \mathrm{a}$ \\
\hline $20-40$ & $0,60 \mathrm{a}$ & $0,55 \mathrm{a}$ & $0,66 \mathrm{a}$ \\
\hline $40-60$ & $0,46 \mathrm{a}$ & $0,54 \mathrm{a}$ & $0,51 \mathrm{a}$ \\
\hline $60-100$ & $0,80 \mathrm{a}$ & $0,90 \mathrm{a}$ & $0,90 \mathrm{a}$ \\
\hline 0-100 & $2,63 \mathrm{a}$ & $2,68 \mathrm{a}$ & $2,78 \mathrm{a}$ \\
\hline
\end{tabular}


Quadro 6. Estoques de carbono e nitrogênio da matéria orgânica leve (C-MOL, N-MOL) nas diversas camadas de solo sob Cerrado, pastagem e eucalipto. Linhas seguidas por letras iguais, dentro de cada profundidade, não diferem entre si $(p>0,05)$ pelo teste LSD de Fisher protegido

\begin{tabular}{|c|c|c|c|}
\hline Camada de solo & Cerrado & Pastagem & Eucalipto \\
\hline \multirow[t]{2}{*}{$\mathrm{cm}$} & $\longrightarrow$ & $\mathrm{tha}^{-1}$ & - \\
\hline & \multicolumn{3}{|c|}{ C - Matéria orgânica leve } \\
\hline $0-10$ & $2,95 \mathrm{~b}$ & $2,78 \mathrm{~b}$ & $6,96 \mathrm{a}$ \\
\hline $10-20$ & $1,91 \mathrm{a}$ & $1,64 \mathrm{a}$ & $2,70 \mathrm{a}$ \\
\hline $20-40$ & $1,91 \mathrm{a}$ & $2,13 \mathrm{a}$ & $2,97 \mathrm{a}$ \\
\hline $40-60$ & $1,22 \mathrm{a}$ & $1,12 \mathrm{a}$ & $1,99 \mathrm{a}$ \\
\hline $60-100$ & $1,87 \mathrm{a}$ & $2,12 \mathrm{a}$ & $2,29 \mathrm{a}$ \\
\hline \multirow[t]{2}{*}{$0-100$} & $9,85 \mathrm{~b}$ & $9,79 \mathrm{~b}$ & $16,92 \mathrm{a}$ \\
\hline & \multicolumn{3}{|c|}{$\mathrm{N}$ - Matéria orgânica leve } \\
\hline $0-10$ & $0,071 \mathrm{~b}$ & $0,071 \mathrm{~b}$ & $0,180 \mathrm{a}$ \\
\hline $10-20$ & $0,043 \mathrm{a}$ & $0,042 \mathrm{a}$ & $0,068 \mathrm{a}$ \\
\hline $20-40$ & $0,043 \mathrm{a}$ & $0,047 \mathrm{a}$ & $0,051 \mathrm{a}$ \\
\hline $40-60$ & $0,022 \mathrm{a}$ & $0,024 \mathrm{a}$ & $0,040 \mathrm{a}$ \\
\hline $60-100$ & $0,041 \mathrm{a}$ & $0,043 \mathrm{a}$ & $0,055 \mathrm{a}$ \\
\hline 0-100 & $0,221 \mathrm{a}$ & $0,227 \mathrm{a}$ & $0,385 \mathrm{a}$ \\
\hline
\end{tabular}

sob Cerrado (39 \% do COT), enquanto que na pastagem (6 \% do COT) não foi observado tal acúmulo. Neste estudo, o cultivo da pastagem não diminuiu o estoque de C-MOL em comparação com a vegetação nativa de Cerrado.

O cultivo de eucalipto adicionou maiores quantidades de $\mathrm{C}$ pela MOL, o que contribui para o aumento da MOS. O solo sob plantio de eucalipto apresentou o maior aporte de resíduos ao solo, e a quantidade de matéria seca da serapilheira de eucalipto foi cerca de 46 e $64 \%$ superior, respectivamente, àquela de Cerrado e de pastagem (Quadro 2). As plantações de eucalipto por apresentarem taxas de crescimento superiores ao Cerrado depositam sobre o solo maior quantidade de folhas e resíduos finos, levando ao aumento da MOL. Além disso, a baixa qualidade nutricional desses resíduos não permite sua rápida decomposição (GamaRodrigues et al., 2003), o que contribui para maior estoque de $\mathrm{C}$ e $\mathrm{N}$ da MOL no solo sob eucalipto em comparação com as outras coberturas.

Para os estoques de N-MOL, houve diferença significativa somente para a camada de $0-10 \mathrm{~cm}$, o solo sob eucalipto apresentou os maiores valores (Quadro 6), em razão do maior aporte de matéria seca e ciclagem de raízes desta cobertura.

As tendências de redução do C-MOL com o aumento da profundidade demonstram que os estoques das frações biologicamente mais ativas do solo foram reduzidas com maior intensidade na camada abaixo da superfície no solo, principalmente no Cerrado. Frações da MOS que têm ciclagem mais rápida, como a BM e a MOL, são extremamente importantes, pois contribuem para ciclagem de nutrientes, visto que são fontes de energia mais prontamente disponíveis para os microrganismos responsáveis por esta ciclagem (Janzen et al., 1992).

\section{Estoque e teor de $\mathrm{C}$ e $\mathrm{N}$ na biomassa microbiana (C-BM, N-BM)}

Para o C-BM, houve diferença significativa $(p<0,05)$ somente para o solo de pastagem na camada de 20-40 cm, que foi menor quando comparado com aqueles de outras coberturas, provavelmente pelo menor aporte de raízes finas provenientes da pastagem. Para o N-BM, não houve diferença significativa entre as coberturas estudadas (Quadro 7).

Em plantações de eucalipto, Gama-Rodrigues et al. (2005) constataram que os teores de C-BM no solo variaram de 43,39 a 401,06 $\mathrm{mg} \mathrm{kg}^{-1}$. No solo deste estudo, na camada de $0-10 \mathrm{~cm}$, os teores de C-BM foram de 374,1, 188,3 e 184,2 $\mathrm{mg} \mathrm{kg}^{-1}$ para Cerrado, pastagem e eucalipto, respectivamente. Maiores valores da proporção C-BM/COT foram observados no solo sob Cerrado $(1,42,0,93,1,32)$, em relação ao solo da pastagem $(0,67,0,87,0,39)$ e eucalipto $(0,67,0,88$, $0,92)$ respectivamente, nas camadas de 0-10, 10-20 e 20-40 cm indicando maior quantidade de $\mathrm{C}$ imobilizado como BM no Cerrado. A maior relação de C-BM/COT em florestas naturais ou regeneradas pode ser explicada com base na maior diversidade do substrato orgânico produzido e aportes destes no local (Anderson \& Domsch, 1978). Os menores valores da proporção $\mathrm{C}-\mathrm{BM} / \mathrm{COT}$ nas diversas camadas dos solos de pastagem e eucalipto poderiam indicar que a disponibilidade de substrato para os microrganismos do solo foi relativamente baixa, e, ou, que as condições foram mais desfavoráveis para o crescimento microbiano.

O C-BM geralmente compreende 2 a $4 \%$ do COT (Gama-Rodrigues, 1999). No entanto, no solo estudado

Quadro 7. Estoques de carbono e de nitrogênio da biomassa microbiana (C-BM, N-BM) em diversas camadas de solo sob Cerrado, pastagem e eucalipto. Linhas seguidas por letras iguais, dentro de cada profundidade, não diferem entre si $(p>0,05)$ pelo teste LSD de Fisher protegido

\begin{tabular}{cccc}
\hline Camada de solo & Cerrado & Pastagem & Eucalipto \\
\hline $\mathrm{cm}$ & \multicolumn{3}{c}{ C- Biomassa microbiana } \\
\cline { 2 - 4 } 0-10 & $0,318 \mathrm{a}$ & $0,160 \mathrm{a}$ & $0,157 \mathrm{a}$ \\
$10-20$ & $0,198 \mathrm{a}$ & $0,208 \mathrm{a}$ & $0,196 \mathrm{a}$ \\
$20-40$ & $0,407 \mathrm{a}$ & $0,136 \mathrm{~b}$ & $0,330 \mathrm{a}$ \\
& & N- Biomassa microbiana \\
$0-10$ & $0,020 \mathrm{a}$ & $0,014 \mathrm{a}$ & $0,017 \mathrm{a}$ \\
$10-20$ & $0,023 \mathrm{a}$ & $0,009 \mathrm{a}$ & $0,028 \mathrm{a}$ \\
$20-40$ & $0,024 \mathrm{a}$ & $0,004 \mathrm{a}$ & $0,028 \mathrm{a}$ \\
\hline
\end{tabular}


esses valores foram menores, em torno de 0,39 e 1,42\% do COT, indicando o pobre crescimento microbiano neste solo. A relação N-BM/COT do solo sob Cerrado também foi maior nas camadas de 0-10 e 10-20 cm, seguida da do eucalipto e da pastagem, demonstrando haver maior quantidade de $\mathrm{N}$ imobilizado como biomassa microbiana no solo de eucalipto do que no de pastagem.

\section{Substituição do carbono do solo devido ao cultivo do eucalipto}

$\mathrm{O}$ valor de $\delta^{13} \mathrm{C}$ encontrado para o solo de Cerrado é maior que aquele reportado para a camada superficial de solo de Cerrado em Sete Lagoas (-24 \%) (Roscoe et al., 2001), mas é menor que aquele reportado para Cerrado da região de Uberlândia-MG (-20,5 \%o) (Wilcke \& Lillienfein, 2004), refletindo maior contribuição de espécies $\mathrm{C} 4$ em relação ao primeiro e menor em relação ao último. As espécies arbóreas de Cerrado possuem rota fotossintética do tipo C3, enquanto as gramíneas são do tipo C4. A importância das gramíneas para a MOS em solos de Cerrado é substanciada pelo fato de que, embora apresentem pequena biomassa da parte aérea (apenas $11 \%$ do total), elas contribuem com $50 \%$ do $\mathrm{C}$ aportado ao solo anualmente, resultando em enriquecimento do C-C4. Possivelmente, isto se deve à rápida ciclagem e ao aporte de $\mathrm{C}$ derivado de raízes finas dessas plantas (Wilcke \& Lillenfein, 2004).

Para calcular a substituição do $\mathrm{C}$ da MOS do Cerrado pelo cultivo do eucalipto por 20 anos, foi utilizado como valor de referência o $\delta^{13} \mathrm{C}$ do solo de Cerrado (-22,84\%o) e $\delta^{13} \mathrm{C}$ de $-27,5 \%$ para florestas plantadas. Foi estimada uma taxa média de perda de $\mathrm{C}$ da ordem de $0,11 \%$. Mais especificamente, nos Latossolos argilosos, como neste estudo, houve ganhos anuais no COT da ordem de $0,145 \%$ na camada de 0 $20 \mathrm{~cm}$ (-0,62\% para espécies perenes/arbóreas cultivadas em solos argilosos) (Zinn et al., 2005). Embora os teores de COT não tenham sido muito alterados, foi constatada ciclagem da MOS neste período. A contribuição do $\mathrm{C}$ derivado do eucalipto para a MOS, após 20 anos de cultivo, foi de $5 \%$ (Quadro 8). Isso indica uma baixa taxa de substituição do $\mathrm{C}$ nativo pelo $\mathrm{C}$ derivado do eucalipto, com uma média anual de $0,25 \%$. Poucos dados estão disponíveis sobre a taxa de substituição do C em áreas de florestas plantadas, mas os dados indicam que as alterações não são tão rápidas. Em Latossolo argiloso na região de Cerrado de Uberlândia-MG, observou-se que $30 \%$ do $\mathrm{C}$ original do solo de Cerrado foi substituído pelo $\mathrm{C}$ derivado de Pinus sp. depois de 20 anos de sua implantação, com uma taxa média anual de substituição da ordem de 1,5\% (Wilcke \& Lillenfein, 2004). Também com base na variação na abundância natural do ${ }^{13} \mathrm{C}$ natural, estimou-se que, na região de Virginópolis, cuja altitude e solos são semelhantes àqueles deste estudo, o cultivo do eucalipto por 32 anos (4 rotações) resultou em taxas médias anuais de substituição do $\mathrm{C}$ da ordem de 0,43, 0,40 e 0,20\%
Quadro 8. Teor de C e abundância natural de ${ }^{13} \mathrm{C}$ de amostras de solo de Cerrado e eucalipto na camada de $0-10 \mathrm{~cm}$

\begin{tabular}{lccc}
\hline & COT solo & $\boldsymbol{\delta}^{13} \mathbf{C}$ solo & $\begin{array}{c}\text { C derivado } \\
\text { do eucalipto }\end{array}$ \\
\hline Cerrado & 3,69 & $\%$ ouc & $\%$ \\
Eucalipto & 3,59 & $-22,84$ & - \\
\hline
\end{tabular}

para as camadas de $0-5,5-10$ e $10-20 \mathrm{~cm}$ de profundidade, respectivamente (Lima et al., 2006). As taxas médias mais elevadas de substituição do $\mathrm{C}$ nativo pelo $\mathrm{C}$ derivado do eucalipto nessas áreas se devem às frequentes intervenções silviculturais na área, além do impacto da colheita, realizadas a cada 7-8 anos.

Os fatores que contribuem para a baixa taxa de substituição do $\mathrm{C}$ provavelmente estão relacionados à ausência de preparo do solo após a implantação, as condições climáticas amenas devido à altitude, especialmente no inverno seco, e à textura muito argilosa, com abundância de óxidos de ferro e alumínio. Esses minerais formam complexos organo-metálicos que contribuem para a estabilização da MOS (Zinn et al., 2005), o que suporta tais hipóteses.

\section{CONCLUSÕES}

1. Houve baixa taxa de substituição do $\mathrm{C}$ nativo pelo $\mathrm{C}$ derivado do eucalipto, possivelmente devido à ausência de preparo do solo após a implantação, a condições climáticas amenas e à textura muito argilosa, com abundância de óxidos de ferro e alumínio.

2. O cultivo do eucalipto proporcionou aumento do estoque de $\mathrm{C}$ em frações mais ativas, como frações de ácido húmico e fúlvico em comparação com o Cerrado e a pastagem, e redução do estoque de $\mathrm{C}$ da fração humina.

3. As frações da matéria orgânica do solo que mais contribuíram para o estoque de carbono e nitrogênio nos solos estudados foram a humina, o ácido húmico, o ácido fúlvico e a matéria orgânica leve. A biomassa microbiana do solo teve pouca contribuição para os estoques de $\mathrm{C}$ e $\mathrm{N}$ do solo.

\section{AGRADECIMENTOS}

Ao CNPq, pela bolsa de doutorado concedida ao primeiro autor. À empresa florestal AcelorMittal Jequitinhonha, pela disponibilização da área experimental e assistência na coleta das amostras de solo. 


\section{LITERATURA CITADA}

ADAMS, M.A. \& ATTIWILL, P.M. Nutrient cycling and nitrogen mineralization in eucalypt forests South-Easthern Australia. I. Nutrient cycling and nitrogen turnover. Plant Soil, 92:319-339, 1986.

ALBRECHT, A. \& KANDJI, S.T. Carbon sequestration in tropical agroforestry systems. Agric. Ecosyst. Environ., 99:15-27, 2003.

ANDERSON, J.P.E. \& DOMSCH, K.H. A physiological method for the quantitative measurement of microbial biomass in soils. Soil Biol. Biochem., 10:215-221, 1978.

BIRD, J.A.; KESSEL, C. \& HORWATH, W.R. Stabilization of ${ }^{13} \mathrm{C}$-carbon and immobilization of ${ }^{15} \mathrm{~N}$-nitrogen from rice straw in humic fractions. Soil Sci. Soc. Am. J., 67:806816, 2003.

BRAGA, J.M. \& DEFELIPO, B.V. Determinação espectrofotométrica de fósforo em extrato de solo e material vegetal. R. Ceres, 21:73-85, 1974.

BROOKES, P.C.; LANDMAN, A.; PRUDEN, G. \& JENKINSON, D.S. Chloroform fumigation and the release of soil nitrogen: A rapid direct extraction method for measuring microbial biomass nitrogen in soil. Soil Biol. Biochem., 17:837-842, 1985.

CANELLAS, L.P.; BALDOTTO, M.A.; BUSATO, J.G.; MARCIANO, C.R.; MENEZES, S.C.; SILVA, N.M.; RUMJANEK, V.M.; VELLOSO, A.C.X.; SIMÕES, M.L. \& MARTIN-NETO, L. Estoque e qualidade da matéria orgânica de um solo cultivado com cana-de-açúcar por longo tempo. R. Bras. Ci. Solo, 31:331-340, 2007.

COBO, J.G.; BARRIOS, E.; KASS, D.C.L. \& THOMAS, R.J. Nitrogen mineralization and crop uptake from surfaceapplied leaves of green manure on a tropical volcanic-ash soil. Biol. Fert. Soil, 36:87-92, 2002.

COELHO, R.M. Influência da vinhaça, da fertilização mineral e do cultivo em características químicas da matéria orgânica e da fração mineral de um Latossolo VermelhoEscuro. Viçosa, MG, Universidade Federal de Viçosa, 1991. 84p. (Tese de Mestrado)

EMPRESA BRASILEIRA DE PESQUISA AGROPECUÁRIA EMBRAPA. Serviço Nacional de levantamento e Conservação de solos. Manual de métodos de análise de solo. Rio de Janeiro, 1997. 212p.

FUNARBE. SAEG-Sistema para Análise Estatística e Genética 5.0. Viçosa, MG, 1993.

GAIFFE, M.; DUQYET, B.; TAVANT, H.; TAVANT, Y. \& BRUCKERT, S. Stabilité biologique et comportement physique d.un complexe argilo-humique placé dans différentes conditions de saturation en calcium ou en potassium. Plant Soil, 77:271-284, 1984.

GAMA-RODRIGUES, E.F.; BARROS, N.F.; GAMARODRIGUES, A.C. \& SANTOS, G.A. Nitrogênio, carbono e atividade da biomassa microbiana do solo em plantações de eucalipto. R. Bras. Ci. Solo, 29:893-901, 2005.
GAMA-RODRIGUES, E.F.; BARROS, N.F \& SANTOS, M.L. Decomposição e liberação de nutrientes do folhedo de espécies florestais nativas em plantios puros e mistos no sudeste da Bahia. R. Bras. Ci. Solo, 27:1021-1031, 2003.

GAMA-RODRIGUES, A.C. \& BARROS, N.F. Ciclagem de nutrientes em floresta natural e em plantios de eucalipto e de dandá no sudeste da Bahia, Brasil. R. Árvore, 26:193207, 2002.

GAMA-RODRIGUES, E.F. Biomassa microbiana e ciclagem de nutrientes. In: SANTOS, G.A. \& CAMARGO, F.A.O., eds. Fundamentos da matéria orgânica do solo: Ecossistemas tropicais e subtropicais. Porto Alegre, Gênesis, 1999. p.227-243.

GOODLAND, R. \& FERRI, M.G. Ecologia do cerrado. São Paulo, Universidade de São Paulo, 1979. 193p.

GOSZ, J.R. Biological factors influencing nutrient supply in forest soils. In: BOWEN, G.D. \& NAMBIAR, E.K.S., eds. Nutrition of plantation forests. London, Academic Press, 1984. p.119-145.

HARIDASAN, M. Nutrição mineral de plantas nativas do Cerrado. R. Bras. Fisiol. Veg., 12:54-64, 2000.

ISLAM, K.R. \& WEIL, R.R. Microwave irradiation of soil for routine measurement of microbial biomass carbon. Biol. Fert. Soils, 27:408-416, 1998.

JANZEN, H.H.; CAMPBELL, C.A.; BRANDT, S.A.; LAFOND, G.P. \& SMITH, T.L. Light fraction organic matter in soils from long term crop rotations. Soil Sci. Soc. Am. J., 56:1799-1806, 1992.

KOLM, L. \& POGGIANI, F. Ciclagem de nutrients em plantações de $E$. grandis submetidas à prática de desbastes progressivos. Sci. For., 63:79-93, 2003.

KUZYAKOV, Y. \& DOMANSKI, G. Carbon input by plants into the soil. J. Plant Nutr. Soil Sci., 163:421-431, 2000

LEITE, L.F.C. Compartimentos e dinâmica da matéria orgânica do solo sob diferentes manejos e sua simulação pelo Modelo Century. Viçosa, MG, Universidade Federal de Viçosa, 2002. 146p. (Tese de Doutorado)

LIMA, A.M.N.; SILVA, I.R.; NEVES, J.C.L.; NOVAIS, R.F.; BARROS, N.F.; MENDONCA, E.S.; SMYTH, T.J.; MOREIRA, M.S. \& LEITE, F.P. Soil organic carbon dynamics following afforestation of degraded pastures with eucalyptus in Southeastern Brazil. For. Ecol. Manag., 235:219-231, 2006.

LIMA, A.M.N.; SILVA, I.R.; NEVES, J.C.L.; NOVAIS, R.F.; BARROS, N.F.; MENDONCA, E.S.; SMYTH, T.J.; MOREIRA, M.S. \& LEITE, F.P. Frações da matéria orgânica do solo após três décadas de cultivo de eucalipto no Vale do Rio Doce-MG. R. Bras. Ci. Solo, 32:1053-1063, 2008.

LONGO, R.M. \& ESPÍNDOLA, C.R. C-orgânico, N-total e substâncias húmicas sob influência da introdução de pastagens (Brachiaria sp.) em áreas de Cerrado e Floresta Amazônica. R. Bras. Ci. Solo, 24:723-729, 2000. 
LOUZADA, J.N.C.; SCHOEREDER, J.H. \& MARCO JR, P. Litter decomposition in semidecidous forest and Eucalyptus spp. Crop: A comparison in Southern Brazil. For. Ecol. Manag., 94:31-36, 1997.

MARTINS, S.V.; BARROS, N.F.; SAMPAIO, O.B. \& GOMES, R.T. Liberação e lixiviação de nutrientes pela queima da manta orgânica de três coberturas vegetais. R. Árvore, 19:149-156, 1995.

MENDONÇA, E.S. Matéria orgânica e características químicas de agregados de um Latossolo Vermelho-Amarelo sob mata natural, seringueira e pastagem. Viçosa, MG, Universidade Federal de Viçosa, 1988. 78p. (Tese de Mestrado)

MILLARD, P.; SOMMERKORN, M. \& GRELET, G. Environmental change and carbon limitation in trees: A biochemical, ecophysiological and ecosystem appraisal. New Phytol., 175:11-28, 2007.

MYERS, R.J.K.; PALM, C.A.; CUEVAS, E.; GUNATILLEKE, I.U.N. \& BROSSARD, M. The synchronisation of nutrient mineralisation and plant nutrient demand. In: WOOMER, P.L. \& SWIFT, M.J., eds. The biological management of tropical soil fertility. New York, Wiley-Sayce Publications, 1994. p.81-112.

NAMBIAR, E.K.S. Pursuit of sustainable plantation forestry. South. Afr. For. J., 184:45-61, 1999.

NEUFELDT, H.; RESCK, D.V.S. \& AYARZA, M.A. Texture and land-use effects on soil organic matter in Cerrado Oxisols, Central Brazil. Geoderma, 107:151-164, 2002.

ORLOV, D.S. Organic substances of Russian soils. Eur. Soil Sci., 31:946-953, 1998 .

PAUSTIAN, K.; SIX, J.; ELLIOTT, E.T. \& HUNT, H.W Management options for reducing $\mathrm{CO}_{2}$ emissions from agricultural soils. Biogeochemistry, 48:147-163, 2000.

ROSCOE, R.; BUURMAN, P.; VELTHORST, E.J. \& VASCONCELLOS, C.A. Soil organic matter dynamics in density and particle size fractions as revealed by the ${ }^{13} \mathrm{C} /$ ${ }^{12} \mathrm{C}$ isotopic ratio in a Cerrado's Oxisol. Geoderma, 104:185-202, 2001.

ROSCOE, R.; BODDEY, R. M. \& SALTON, J.C. Sistemas de manejo e matéria orgânica do solo. In: ROSCOE, R.; MERCANTE, F.M. \& SALTON, J.C., orgs. Dinâmica da matéria orgânica do solo em sistemas conservacionistas: Modelagem matemática e métodos auxiliares. Dourados, Embrapa Agropecuária Oeste, 2006. p.17-41.
SKORUPA, A.L.A. Acumulação e decomposição de serapilheira em povoamento de eucalipto, na Região do Baixo do Rio Doce-MG. Viçosa, MG, Universidade Federal de Viçosa, 2001. 64p. (Tese de Mestrado)

SOHI, S.P.; MAHIEU, N.; ARAH, J.R.M.; POWLSON, D.S.; MADARI, B. \& GAUNT, J.L. A procedure for isolating soil organic matter fractions suitable for modeling. Soil Sci. Soc. Am. J., 65:1121-1128, 2001.

SPARLING, G.P. \& WEST, A.W. A direct extration method to estimate soil microbial C: calibration in situ using microbial respiration and ${ }^{14} \mathrm{C}$ labeled cells. Soil Biol. Biochem., 20:337-343, 1988.

STEEL, R.G.D.; TORRIE, J.H. \& DICKEY, D.A. Principles and procedures of statistics: A biometrical approach. New York, Mc Graw-Hill, 1997. 666p.

SWIFT, R.S. Method for extraction of IHSS soil fulvic and humic acids. In: SPARKS, D.L.; PAGE, A.L.; HELMKE, P.A.; LOEPPERT, R.H.; SOLTANPOUR, P.N.; TABATABAI, M.A.; JOHNSTON, C.T. \& SUMMER, M.E., eds. Methods of soil analysis: Chemical methods. Madison, Soil Science Society of America, 1996. Part 3. p.10181020 .

TEDESCO, H.J.; VOLKWEISS, S.J. \& BOHNEN, H. Análises de solo, plantas e outros materiais. Porto Alegre, Universidade Federal do Rio Grande do Rio Grande do Sul, 1985. 50p. (Boletim Técnico, 5)

VIEIRA, S.A. Efeito das plantações florestais (Eucalyptus sp.) sobre a dinâmica de nutrientes em região de Cerrado do Estado de São Paulo. Piracicaba, Escola Superior de Agricultura Luiz de Queiróz, Universidade de São Paulo, 1998. 73p. (Tese de Mestrado)

VITORELLO, V.A.; CERRI, C.C.; ANDREAUX, F.; FELLER, C. \& VICTORIA, R.L. Organic matter and natural carbon13 distribution in forested and cultivated Oxisols. Soil Sci. Soc. Am. J., 53:773-778, 1989.

WHIETHÖLTER, S. Nitrogênio no solo sob plantio direto. R. Plantio Direto, 58:38-42, 2000.

WILCKE, W. \& LILIENFEIN, J. Soil carbon-13 natural abundance under native and managed vegetation in Brazil. Soil Sci. Soc. Am. J., 68:827-832, 2004.

YEOMANS, J.C. \& BREMNER, J.M. A rapid and precise method for routine determination of organic carbon in soil. Comm. Soil Sci. Plant Anal., 19:1467-1476, 1988.

ZINN, Y.L.; LAL, R. \& RESCK, D.V.S. Changes in soil organic carbon stocks under agriculture in Brazil. Soil Till. Res., 84:28-40, 2005. 